\title{
Archetypal trajectories of social, psychological, and spiritual wellbeing and distress in family care givers of patients with lung cancer: secondary analysis of serial qualitative interviews
}

\author{
Scott A Murray, St Columba's Hospice professor of primary palliative care, Marilyn Kendall, senior research \\ fellow, Kirsty Boyd, honorary clinical senior lecturer, Liz Grant, senior lecturer, Gill Highet, research fellow, Aziz \\ Sheikh, professor of primary care research and development
}

\begin{abstract}
Primary Palliative Care Research Group, Centre for Population Health Sciences: General Practice Section, University of Edinburgh, Edinburgh EH8 9DX

Correspondence to: S A Murray scott.murray@ed.ac.uk
\end{abstract}

Cite this as: $B M J$ 2010;304:C2581 doi:10.1136/bmi.c2581

\section{ABSTRACT}

Objective To assess if family care givers of patients with lung cancer experience the patterns of social, psychological, and spiritual wellbeing and distress typical of the patient, from diagnosis to death.

Design Secondary analysis of serial qualitative interviews carried out every three months for up to a year or to bereavement.

Setting South east Scotland.

Participants 19 patients with lung cancer and their 19 family carers, totalling 88 interviews ( 42 with patients and 46 with carers).

Results Carers followed clear patterns of social, psychological, and spiritual wellbeing and distress that mirrored the experiences of those for whom they were caring, with some carers also experiencing deterioration in physical health that impacted on their ability to care. Psychological and spiritual distress were particularly dynamic and commonly experienced. In addition to the "Why us?" response, witnessing suffering triggered personal reflections in carers on the meaning and purpose of life. Certain key time points in the illness tended to be particularly problematic for both carers and patients: at diagnosis, at home after initial treatment, at recurrence, and during the terminal stage.

Conclusions Family carers witness and share much of the illness experience of the dying patient. The multidimensional experience of distress suffered by patients with lung cancer was reflected in the suffering of their carers in the social, psychological, and spiritual domains, with psychological and spiritual distress being most pronounced. Carers may need to be supported throughout the period of illness not just in the terminal phase and during bereavement, as currently tends to be the case.

\section{INTRODUCTION}

The clinical course of people with fatal progressive illness seems to follow three main patterns (see web extra). ${ }^{12}$ The first is a short period of relatively predictable decline in the last weeks or months of life, as typified by patients with lung cancer. In the second trajectory, slow decline is punctuated by acute exacerbations, as seen more typically in patients with organ failure. The third trajectory is characterised by poor long term functional status, with very slow decline; elderly patients with dementia or frailty fit into this category. These trajectories provide a way to describe generalities about large discernible patient groups, each with different time courses of illness, service needs, priorities for care, and barriers to reliable high quality care. $^{3}$

Taking the first of these trajectories, we have previously described characteristic patterns of social, psychological, and spiritual wellbeing in people with progressive lung cancer (using this as an exemplar cancer), from diagnosis to death. ${ }^{4}$ In lung cancer, the physical and social trajectories appeared to decline in parallel over the period of disease. Patients, however, tended to describe heightened psychological and spiritual distress at four key transition points: at diagnosis, at home after initial treatment, at recurrence, and in the terminal stage (see web extra). An appreciation of these archetypical patterns in those with lung cancer can help professionals, patients, and carers anticipate when and in which dimension distress is likely, so enabling preparation and planning of care.

Since 1995 UK health policy has acknowledged that informal carers of patients with cancer have views and preferences that should be considered alongside those of patients, and that services should also support carers as well as patients. ${ }^{5-7}$ Cancer is recognised increasingly as affecting all the family, with psychological distress reverberating substantially throughout the nuclear family and perhaps beyond. ${ }^{8-10}$ A growing body of research has documented the quality of life of cancer survivors, but the impact on family care givers is less well studied. ${ }^{11}$

Although quality of life is a multidimensional construct, psychological distress is the best researched 


\begin{tabular}{|c|c|c|c|c|c|}
\hline \multicolumn{6}{|c|}{ Details of patients with lung cancer and their informal family carers who were interviewed } \\
\hline Sex & Age & $\begin{array}{l}\text { Carstairs' deprivation } \\
\text { category* }\end{array}$ & $\begin{array}{l}\text { Histology } \\
\text { of lung cancer }\end{array}$ & $\begin{array}{l}\text { Patient status } \\
\text { at end of study }\end{array}$ & $\begin{array}{l}\text { Informal } \\
\text { carer }\end{array}$ \\
\hline Woman & 74 & 2 & NA & Alive & $\begin{array}{l}\text { Daughter- } \\
\text { in-law }\end{array}$ \\
\hline Man & 55 & 4 & Non-small cell & Alive & Wife \\
\hline Woman & 58 & 3 & Small cell & Died & Husband \\
\hline Woman & 64 & 1 & Adenocarcinoma & Died & Husband \\
\hline Woman & 72 & 1 & Non-small cell & Withdrew owing to husband & Husband \\
\hline Man & 64 & 1 & Small cell & Alive & Wife \\
\hline Man & 71 & 3 & Squamous & Alive & Wife \\
\hline Man & 71 & 4 & Non-small cell & Died & Wife \\
\hline Man & 48 & 5 & Non-small cell & Died & Wife \\
\hline Man & 36 & 3 & Non-small cell & Alive & Wife \\
\hline Woman & 79 & 6 & NA & $\begin{array}{l}\text { Withdrew owing to bowel } \\
\text { cancer }\end{array}$ & Husband \\
\hline Man & 73 & 4 & NA & Withdrew owing to wife & Wife \\
\hline Woman & 66 & 4 & Small cell & Died & Husband \\
\hline Woman & 75 & 4 & NA & Withdrew, moved & Husband \\
\hline Man & 54 & 4 & Squamous & Died & Wife \\
\hline Man & 76 & 1 & NA & Withdrew, ill from treatment & Wife \\
\hline Woman & 44 & 6 & Adenocarcinoma & Alive & Husband \\
\hline Woman & 68 & NA & Small cell & Died & Husband \\
\hline Man & 71 & NA & Non-small cell & Alive & Wife \\
\hline
\end{tabular}

$\mathrm{NA}=$ not available

*1 most affluent, 7 most deprived
From the first and second studies, we analysed 17 patient and carer interview dyads, which described the multidimensional illness experience of patients with lung cancer and their carers every three months from diagnosis to death or for 12 months from the initial interview. ${ }^{1920}$ Most patients had been identified and recruited by a lung cancer specialist at initial diagnosis and before palliative chemotherapy or radiotherapy. The patient consent form stated that we also wanted to speak with a relative or carer if one existed. Interviews were semistructured and carried out in the home setting every three months, when patients and carers were asked about the main issues or problems they had or patients perceived their carer had as the illness progressed. From the third study we included two further patient and carer case studies, which specifically explored spiritual needs and distress over time. In about half of these interviews, the patient and carer chose to be interviewed together. We used an established definition of spiritual distress, which relates such discomfort to the meaning and purpose of life and which recognises that people may or may not use religious vocabulary to express this. ${ }^{24}$ We defined the social domain as relating to the carer's ability to network and generally socialise and the psychological domain as relating to their mental wellbeing, including anxiety and depression. These interviews had been recorded, transcribed verbatim with accompanying field notes, and analysed with the support of NVivo. ${ }^{25}$

We reanalysed these data thematically for references from the patient or carer to the specific needs of the family carers, and then mapped these over time from diagnosis to death. We considered that all patients with advanced disease have physical, social, psychological, and spiritual or existential dimensions and needs, and such needs can cause distress if particularly acute or unmet. We explored if typical trajectories existed by considering and plotting at what stage in the illness pathway we had carried out each interview and what dimensions of distress in carers were vocalised by the patients and carers at these time points. Further details of the recruitment of participants, data generation, and analysis of these three studies can be found in our two recent papers on the utility of longitudinal qualitative methods and also multiperspective interviewing in end of life research. ${ }^{2627}$

\section{RESULTS}

Overall, 88 interviews (42 with patients and 46 with carers) with 19 patients (10 men and nine women) and their case linked family carers were analysed. Patients were aged 44-79 years. The number of interviews ranged from 2-8 within each patient and carer case study. Carers comprised 17 spouses and two daughters; two carers were of South Asian origin. The table provides further details.

Archetypal trajectories of social, psychological, and spiritual wellbeing were found in carers, with the multidimensional experience of distress suffered by their loved ones being reflected in their own suffering and being most pronounced for psychological and spiritual 


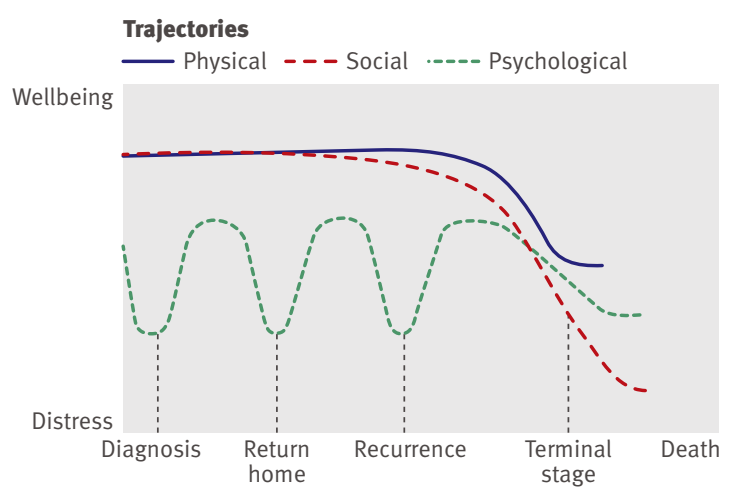

Fig 1| Fluctuations in psychological wellbeing in family carers of patients with lung cancer

distress. As carers' multidimensional needs were dynamic and variable, quotations and graphic representations are presented to highlight and explain the patterns that emerged.

\section{Physical wellbeing}

Data on the health status of carers were relatively sparse, but where present these data suggested that their own physical health problems could compromise their capacity to care; some also felt exhausted and that they were sharing the illness, especially as time went on and death approached, as reflected on by one carer:

I feel that it's my responsibility [to clean patient when goes to toilet] and I will carry on as long as I can ... If she needs more help than that, we'll have to get it as I have back problems (carer)

\section{Social wellbeing}

As patients became progressively unwell, the carer often felt less and less able to leave them alone, restricting their normal social contacts, hobbies, work, and even holidays:

Me taking the lung cancer, that really more or less blew her, and eh, well she was working on the buses as a cleaner eh so she had to give that up... she finally packed that in just the other week and this is her starting this new job and she's just pleased to get that couple of hours, it's a break away from here, eh (patient) The whole family has been looking forward to a holiday together in Corfu in September, but I'm not sure now we will be able to go (carer)

Other family members might also be more reluctant to visit, leaving the carer feeling physically and socially isolated, as if they too had moved into a life centred on illness and were in a parallel world with the patient. This diminishment of existing social contacts added to the sense of loss and isolation when bereaved.

\section{Psychological wellbeing}

Carers, like patients, often felt they were on an emotional rollercoaster, experiencing peaks and troughs at key times of stress and uncertainty in the cancer trajectory (fig 1).

\section{Diagnosis}

The time of diagnosis was surrounded with particularly acute anxiety:

We were just absolutely gobsmacked [shattered] (patient)

It's just like being hit by a train, isn't it?... It's just like, you, you just hear the word ... [a month on] you still cannae take it in (carer)

\section{Return home}

At home after initial treatment, trying to communicate in itself was distressing, and the carer could feel increasingly worn down and under pressure:

It's much harder for him, he hates me talking about it, it distresses him, which isn't fair (patient)

Tired of it! Yes, you get fed up ... it's going on a long time and ... yes. I think we do feel that the pressure is getting to us really. It has been hard, it's not easy for us to say that. . . . But yes, it is difficult (carer)

Yeah... I'd say now, a wee bit depressed, eh, wearing you down, kind of thing, you know? Oooh! (carer)

\section{Recurrence}

When the disease recurred carers might empathise with the worry the patients had at that stage, but sometimes had to deal with difficult behaviour along with their own concerns that their partner might suddenly die:

Nothing worse than thinking it is ... it must be incredible for cancer patients, a terrible thing to live with He went through a phase where he [husband] was really aggressive and very moody and he was terrible —it just drives me crazy

\section{Terminal stage}

At the terminal stage, one carer sat up at night worried that her husband might die soon:

These last few nights when I've been sat up with him because of these hiccups, it's just gone on and on and it's really made me start to wonder what it will be like, you know? Sometimes I wonder, is this it? Is this the end?

\section{Spiritual wellbeing}

Spiritual distress was also common and dynamic (fig 2).

\section{Diagnosis}

At diagnosis, one carer related that the first thing she and her late husband thought of was to get married, as they had re-evaluated relationships and values:

They managed to arrange the wedding quite quick ... well, very quickly and people were very helpful and it was a very useful thing for bringing everyone together and the whole of the family played their part and it was something to focus on, something to look forward to ... something that was enjoyable 


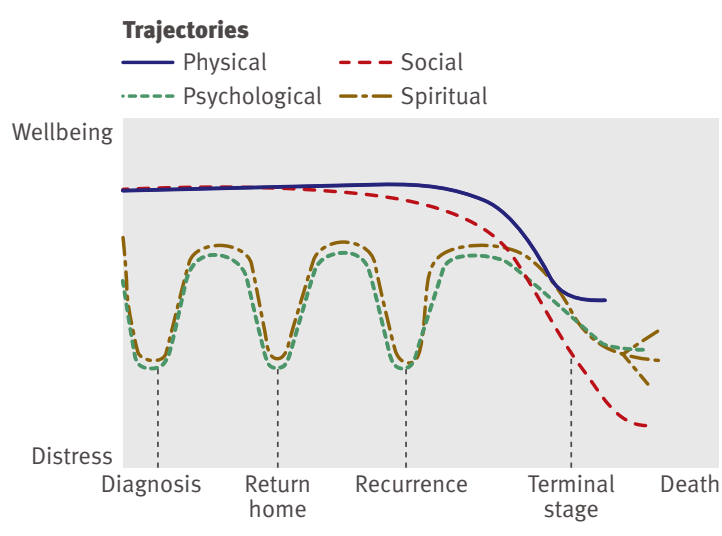

Fig 2 Fluctuations of spiritual wellbeing mapped with other trajectories of physical, social, and psychological wellbeing in family carers of patients with lung cancer

\section{Return home}

With the patient back home, some carers tried intellectually to accept the diagnosis and prognosis, but were still emotionally upset:

Well, it's just something I've got to accept. Nothing I can do about it, so what's the use of worrying about it? I would have said just enjoy each day as it comes, but that's just it, with all this, you cannae enjoy yourself

\section{Recurrence}

One carer, when learning that the patient's cancer was advanced, found solace in retreating to the bathroom to pray, whereas another was confused that God did not seem to be present in their suffering:

It kind of makes you a bit angry. You think, "is there a god?" Sometimes you think, "how can He do that?" I don't know, I'm kind of mixed up about all that

\section{Terminal stage}

At the terminal stage, another carer felt her hopes would be dashed if her husband left her house, their sanctuary:

All my hope will have gone if he is to go into the hos-

pice. I really, really don't want him to die in there

\section{DISCUSSION}

Family carers witness and share much of the illness experience of the dying person, albeit in their own distinct ways. The multidimensional experience of distress suffered by patients with lung cancer tends to be mirrored by their carers, mainly in the social, psychological, and spiritual domains, although for some carers there may also be physical implications. The patterns that we describe resonate with the turbulent experiences of patients, these being shaped to an extent by the nature of the illness and the care available. Our work suggests that in addition to the recognised bereavement phase the key time points to focus psychological and existential support for carers are at diagnosis, at home after initial treatment, at recurrence, and in the terminal stage. As these key time points are the same for patients, the needs of patients and carers should be dealt with in parallel.

\section{Strengths of this study}

Secondary analysis of qualitative datasets is now seen internationally as an important, valid, and expanding area of inquiry. There is a long tradition of reusing such data; one study, for example, recently looked at data as far back as 1937 to inform analysis of change within particular social and cultural groups over time, concluding that this technique is most fruitful when dealing with longitudinal qualitative data, as is the case in this analysis. ${ }^{28}$ Indeed, the Economic and Social Research Council now requires all qualitative research projects to deposit their datasets with Economic and Social Data Service's Qualidata to make them available for reanalysis by future qualitative researchers. The costly and time consuming collection of qualitative data, when the collection is publicly funded, leads to an economic imperative to encourage the reuse and reanalysis of these datasets by later researchers or, preferably, by the same research team at a later date. $^{2329}$ The data in this paper were collected for the original studies by the same research team using a longitudinal multiperspective qualitative design that was common to all three primary studies. The key strengths of this study design have recently been reviewed..$^{262730}$ The innovative concept of charting these trajectories gives easy visual access to the notion of dynamic patterns, using a concept familiar to clinicians.

\section{Limitations of the trajectory approach}

Although most medical conditions have "typical presentations," cases present and evolve in various ways. Patients may die at any point in the trajectory, and the timescale is variable within specific cancers as well as between different cancers. Patient distress in one dimension can increase distress in another, such as anxiety amplifying pain, and the availability of services also alters the illness experience. These factors may also affect carers' experiences, as may their education and information about the disease. Illnesses can only be experienced in a family or community context, which can be highly individual and change according to care setting. Thus there is a danger of stereotyping on the basis of archetypal trajectories, and further work is needed to explore these and other patterns or subtrajectories in patients and carers. As a safeguard to stereotyping, we looked for alternative explanations and disconfirming data and noted several outlying cases when, for example, carers drew on resources within themselves or from others to moderate the distress that might otherwise have occurred. The predictive value at the level of the individual may be limited, but there are none the less clear policy implications for providing adequate services for carers so that services are configured to be person centred and timely. Theoretical limitations also exist in analysing data in this way when we were not pursuing purposeful sampling around carer distress, although qualitative analysis is in fact "making new data out of old." 29 


\section{WHAT IS ALREADY KNOWN ON THIS TOPIC}

Typical trajectories of social, psychological, and spiritual wellbeing and distress have been described for patients with progressive lung cancer

\section{WHAT THIS STUDY ADDS}

Family care givers may also experience typical patterns of wellbeing and distress in these dimensions in parallel with patients

Psychosocial and existential support for patients with lung cancer and their family carers should be offered not just in the terminal phase or in bereavement but at four key transitions: at diagnosis, at home after initial treatment, at recurrence, and in the terminal stage

\section{Comparison with previous literature}

Our work adds to the current literature, which suggests an association between patients' and carers' psychological distress and that this increases as the cancer progresses. ${ }^{13-16}$ Little information is available as to patterns of progression of carers' distress over time, although distress may be maximal in patients at diagnosis, recurrence, and in the final days. ${ }^{31}$ Although patients and carers may display distress at similar times, as the carer may empathise with the patient's suffering as well as having their own personal issues, one study found that carers experienced greater distress than the patient when the patient was receiving treatment, but that the situation reversed shortly after, with the patients reporting more distress than the carers. ${ }^{32} \mathrm{We}$ failed to find reports of other qualitative or quantitative studies using serial interview or questionnaire dyads to explore dynamic changes in physical, social, psychological, and spiritual needs over time.

\section{Research and clinical implications}

These findings now need to be tested in further prospective studies of patient and carer interview dyads, specifically setting out to explore the multidimensional dynamic experience of carers and their perceptions of how their care could best be improved. Methodological development around frequency of interviews or triggers for reinterviews is needed, and the added benefit of having case linked patient views should be explored. Further research is also needed in nonmalignant conditions, where we have also started to identify typical patterns of social and psychological wellbeing. ${ }^{24}$

This work does suggest that proactive support and management should be targeted at critical stages to minimise the risk of predictable distress in carers. ${ }^{12}$ It may also be empowering for carers to know that it is common to feel stressed and in need of support at certain times. Clinical implications may be especially relevant in primary care, where the patient and carer are often both supported by the same clinicians. A previous study of carers of patients with lung cancer found that the main component of emotional support for them was having someone to listen and talk to. ${ }^{33} \mathrm{We}$ suggest this support should be available not just in the terminal phase or in bereavement but at the four key transitions: at diagnosis, at home after treatment, at recurrence, and in the terminal stage. These findings are likely to apply to carers of people affected by other cancers that are characterised by rapid decline. We acknowledge, however, that care giving has many positive aspects, that many care givers are resilient and appreciate the opportunity to care, and that many will not suffer clinically significant distress or complicated grief.

We thank the participants and the researchers who worked on these studies and the reviewers of an earlier version of this manuscript. Contributors: SAM, MK, and AS conceived the paper. All the authors wrote the paper and approved the final draft. SAM is the guarantor. Funding: The Chief Scientist's Office of the Scottish government funded the studies.

Competing interests: All authors have completed the unified competing interest form at www.icmje.org/coi_disclosure.pdf (available on request from the corresponding author) and declare (1) no financial support for the submitted work from anyone other than their employer; (2) no financial relationships with commercial entities that might have an interest in the submitted work; (3) no spouses, partners, or children with relationships with commercial entities that might have an interest in the submitted work; and (4) no non-financial interests that may be relevant to the submitted work.

Ethical approval: This was obtained from the south east of Scotland research ethics committee before each of the three studies from which we analysed data.

Data sharing: No additional data available.

1 Lunney JR, Lynn J, Foley DS, Lipson S, Guralnik JM. Patterns of functional decline at the end of life. JAMA 2003;289:2387-92.

2 Murray SA, Kendall M, Boyd K, Sheikh A. Illness trajectories and palliative care. BMJ 2005;330:1007-11.

3 Lynn J. Reliable comfort and meaningfulness. Making a Difference campaign. BMJ 2008;336:958-9.

4 Murray SA, Kendall M, Grant E, Boyd K, Barclay S, Sheikh A. Patterns of social psychological and spiritual decline towards the end of life in lung cancer. J Pain Sympt Man 2007;34:393-402.

5 Department of Health. A policy framework for commissioning cancer services. HMSO, 1995.

6 Department of Health. The NHS cancer plan: a plan for investment, a plan for reform. Stationery Office, 2000.

7 Department of Health. End of life strategy. Stationery Office, 2008.

8 Manne SL. Cancer in the marital context: a review of the literature. Cancer Invest 2007;16:188-202.

9 Kissanne D, Bloch S, Burns WI, Mackenzie D, Posterino M. Psychological morbidity in the families of patients with cancer. Psychooncology 1994;3:47-56.

10 Bowman KF, Deimling GT, Smerglia V, Sage P, Kahana B. Appraisal of the cancer experience by older long-term survivors. Psychooncology 2003;12:226-38.

11 Kim Y, Given BA. Quality of life of family caregivers of cancer survivors across the trajectory of the illness. Cancer 2008;112:2556-68.

$12 \operatorname{Kim}$ Y, Spillers R. Quality of life of family caregivers at 2 years after a relative's cancer diagnosis. Psychooncology 2009; published online 27 Apr.

13 Pitceathly C, Maguire P. The psychological impact of cancer on patients' partners and other key relatives: a review. Eur J Cancer 2003;39:1517-24.

14 Hodges LJ, Humphris GM, Macfarlane G. A meta-analytic investigation of the relationship between the psychological distress of cancer patients and their carers. Soc Sci Med 2005;60:1-12.

15 Persson C, Ostlund U, Wennman-Larsen A, Wengstorm Y, Gustavsson P. Health-related quality of life in significant others of patients dying from lung cancer. Palliat Med 2008;22:239-47.

16 Ostlund U, Wennman-Larsen A, Persson C, Gustavsson P, Wengstrom $Y$. Mental health in significant others of patients dying from lung cancer. Psychooncology 2010;19:29-37.

17 Kurtz ME, Kurtz JC, Given CW, Given BA. Depression and physical health among family caregivers of geriatric patients with cancer-a longitudinal view. Med Sci Monit 2004;10:447-56.

18 Kim Y, Wellisch DK, Spillers RL, Crammer C. Psychological distress of female cancer caregivers: effects of type of cancer and caregivers' spirituality. Support Care Cancer 2007;15:1367-74.

19 Murray SA, Boyd K, Kendall M, Worth A, Benton TF, Clausen H. Dying of lung cancer or cardiac failure: prospective qualitative interview study of patients and their carers in the community. $B M$ J 2002;325:929-32. 
20 Worth A, Irshad T, Bhopal R, Brown D, Lawton J, Grant E, et al. Vulnerability and access to care for South Asian Sikh and Muslim patients with life limiting illness in Scotland: prospective longitudinal qualitative study. BMJ 2009;338:b183.

21 Grant E, Murray SA, Kendall M, Boyd K, Tilley S, Ryan D. Spiritual issues and needs: perspectives from patients with advanced cance and non malignant disease. A qualitative study. Palliat Support Care 2004;2:371-8

22 Forum: Qualitative Social Research. Secondary analysis of qualitative data. 2005. www.qualitative-research.net/fqs/fqs-e/ inhalt1-05-e.htm.

23 Heaton J. Reworking qualitative data. Sage, 2004.

24 Murray SA, Kendall M, Boyd K, Worth A, Benton TF. Exploring the spiritual needs of people dying of lung cancer or heart failure: $a$ prospective qualitative interview study of patients and their carers. Palliat Med 2004;18:39-45.

25 QSR NVivo version 7. www.qsrinternational.com.

26 Murray S, Kendall M, Carduff E, Worth A, Harris F, Lloyd A, et al. Use of serial qualitative interviews to understand patients' evolving experiences and needs. BMJ 2009;3009:b3702.
27 Kendall M, Murray SA, Carduff E, Worth A, Harris F, Lloyd A, et al. Use of multi-perspective qualitative interviews to understand patients' and carers' beliefs, experiences and needs. BMJ 2009;339:b4122.

28 Savage M. Changing social class identities in post-war Britain: perspectives from Mass-Observation. 2007. www.socresonline.org. uk/12/3/6.html.

29 Moore N. (Re)using qualitative data? 2007. www.socresonline.org. uk/12/3/1.html.

30 Murray S, Sheikh A. Serial interviews for patients with progressive diseases. Lancet 2006;368:901-2.

31 The AM, Hak T, Koeter G, van der Wal G. Collusion in doctor-patient communication about imminent death: an ethnographic study. BM 2000;321:1376-81.

32 Northouse LL. A longitudinal study of the adjustment of patients and husbands to breast cancer. Oncol Nurs Forum 1989;16:511-6.

33 Ryan PJ, Howell V, Jones J. Lung cancer, caring for the caregivers. A qualitative study of providing pro-active social support targeted to the carers of patients with lung cancer. Palliat Med 2008;22:233-8.

Accepted: 9 March 2010 